\title{
Job Incentives And Career Knowledge As Predictors Of Workers Job Performance Among Employees Of Transmission Company Of Nigeria (TCN)
}

\author{
Zaccheaus Olonade ${ }^{1 *}$,Micheal Boyede ${ }^{2}$ \\ 1. Department of Human Resource Development, Osun State University, Osogbo, Nigeria. \\ 2. Department of Human Resource Development Osun State University, Osogbo, Nigeria.
}

\begin{abstract}
This study investigated job incentives and career knowledge as predictors of worker job performance in Transmission Company of Nigeria (TCN). The study was for the purpose of ascertaining whether job incentives significantly contributed to worker job performance among the workers in Transmission Company of Nigeria (TCN) or not. In the study, primary data was used. Survey research design was used. Primary data was collected through self-administered structured questionnaire. Descriptive and inferential statistics were used to analyze the data. A total of 100 respondents from the organization were selected for the study using stratified Proportionate sampling technique. The researcher utilized three sets of questionnaire titled Job Incentives Scale, Workers Job Performance Scale and Career Knowledge Scale. Pearson's Correlation was used to test the hypotheses. The findings of the study revealed that Job Incentives has weak negative relationship with job performance among worker of Transmission Company of Nigeria $[\mathrm{r}(96)=-0.11, \mathrm{p}>0.05]$, also, findings revealed that career knowledge has weak positive relationship with job performance among workers of Transmission Company of Nigeria $[\mathrm{r}(96)=0.119, \mathrm{p}>0.05]$. It is recommended that employers should concentrate more on adequate job incentives and rewards to their workers to elicit positive attitude from them at work; and achieve job satisfaction which improves employee productivity and corporate performance.
\end{abstract}

Keywords: Job Incentives, Career Knowledge, Workers, Job Performance.

DOI: $10.7176 /$ RHSS/9-14-15

Publication date:July $31^{\text {st }} 2019$

\section{INTRODUCTION}

Incentives are considered one of the most important factors that encourage workers to put forth great efforts and work more efficiently. It is because incentives and reward system direct workers capabilities into more efficiency in their work in an attempt to achieve the institution's goals (Gana and Bababe, 2011). In addition, the absence of the suitable incentives may negatively affect the hardworking employee's performance; it may also weaken their productivity at work which decreases the chances of attaining the promising goals of the institution (Palmer, 2012). Such incentives are a significant factor in encouraging employees and increasing their enthusiasm at work which results in improving the general performance and increasing the productivity. Incentives, also, help in attaining job satisfaction which increases the interaction between the employee and the organization. However, in many companies' incentives and reward system are designed by human resource department while the evaluation of employees and organization performance are done by the finance department. As such, there is an integration issue as both departments tend to isolate with each other. Furthermore, usually the incentives and the reward system are designed by the top management based on their perceptions without consulting the employee at the lower level. In this case, the incentives and the reward system may not be able to achieve the employee's satisfaction and such system will not be able to change their attitude and behavior toward the organization as they feel that their contribution to the organization are not well recognized. Therefore, the present study tends to overcome this issue and provides insight and recommendations for the Jordanian travel and tourism organizations by determining how incentives and the rewards system influencing the employee's performance.

\section{STATEMENT OF THE PROBLEMS}

So many problems have been found or discovered to be a hindrance to the entire business sectors. Most enterprise has not achieved significant supply of corporative workforce and optimum productivity. It has been noted that workers often complain about their wages and salary administration, poor working condition, welfare, effective supervision, provision of adequate machinery and materials at work place, provision of proper appliance and their maintenances etc. the above complaints are indications that things are not going smoothly 
with the workers.

On the other hand, management always asks why the workers are no longer productive or low level of productivity in the organization. The solution to the above management questions often point to the managers that employees are either not properly motivated or not satisfied with their job. Except opportunities are provided at work place to satisfy the workers needs they will continue to have decreased production and performance will always remain low. It was such alarming question that led some human relation experts into finding out what gives on individual's job performance. These relationships between job incentives and job performance have made many researchers work intensively on this area to find out dependable solutions to the problems.

\section{OBJECTIVES OF THE STUDY}

The broad objective of the study is to examine job incentives and career knowledge as predictors of worker's job performance in Transmission Company of Nigeria (TCN). The specific objectives are:

to determine the relationship between job incentives on workers performance in Transmission Company of Nigeria $(\mathrm{TCN})$ also to examine the level of career knowledge of workers on workers performance in Transmission Company of Nigeria (TCN).

\section{RESEARCH HYPOTHESES}

Hypothesis 1: Job Incentives will not significantly influence Job Performance of employees Transmission Company of Nigeria (TCN)

Hypothesis 2: Career Knowledge will not significantly influence Job Performance of employees Transmission Company of Nigeria (TCN)

\section{REVIEW OF RELATED LITERATURE}

\section{Hierarchy of needs Theory}

The hierarchy of need that was propounded by Abraham Maslow in 1943. Maslow opined that man is a working animal who works towards the satisfaction of his needs. His view was that human unfold in a hierarchical order starting from the lower needs and that once a need is satisfied another one manifests itself. That probably account for the popular name "The Hierarchy of needs" given to the theory. Those needs develop from the very basic needs of life, through a series of level to the more complicated higher level of motives. Maslow graded the needs of man into the following hierarchy: a) Physiological needs which are necessary to human survival, example food, water, sleep rest etc.; b) Safety needs, example security, order, stability, non-hostility; c) Social or love needs example belongingness and friendly relationship with fellow citizens, need of companionship and association with others, affection and identification; d) Ego or esteem or self-expression need, example selfrespect, prestige, success etc and e); Self-actualization or self-fulfillment needs.

These basic needs are related to one another and one that is satisfied actuates the other higher one, thus making man a perpetually waiting animal. The theory however treats all human being a like, forgetting the individuality of each man and that what motivates one may not motivate another. The differences in background, upbringing, education and aspiration of individuals all have impact on human needs. This is evident in the fact that when every individual hustle for the basic needs of survival and safety, there is a variation henceforth. Others problems the theory did not look into include the problems of values in any definitive motivation theory, the relationship between appetites, desires needs and what is good for the organism, the etiology of the basic needs and their possible derivation in early childhood, ate definition of motivational concepts i.e. drives, desire, wish, needs, goals implication of our theory of hedonistic theory, the nature of the uncompleted act, of success and failure and of aspiration level, the role of association, habit and conditioning, relation to the theory of interpersonal relations, implications for psychotherapy, implication for theory of society, the theory of Selfishness, the relation between needs and cultural patterns, and the relation between this theory and all parts theory of functional autonomy.

\section{Motivator-Hygiene Theory}

Fredrick Herzberg developed the motivator-hygiene theory in 1959. This theory is closely related to Maslow's hierarchy of needs but relates move specifically to how individuals are motivated in the workplace. Based on his research Herzberg argued that meeting the lower-level needs (hygiene factors) of individuals would not motivate them to exert effort, but would only prevent them from being dissatisfied. Only if higher-level needs (motivators) were met would individuals be motivated.

The implication for managers of the motivator-hygiene theory is that meeting employees lower-level needs by improving pay, benefits, safety, and other job-contextual factors will prevent employees from becoming actively dissatisfied but will not motivate them to exert additional effort toward better performance. To motivate works or 
employees, according to the theory, managers must focus on changing the intrinsic nature and content of jobs themselves by "enriching" them to increase employees"e autonomy and their opportunities to take on additional responsibility, gain recognition, and develop their skills and careers. An analysis of these interviews led Herzberg to conclude that certain factors led to job satisfaction, which he termed motivators and certain factors found in the two groups are Hygiene factors include: Leading to dissatisfaction, Policies and Administration, Supervision, Working conditions, Money, Job security and Status; and Motivators include: Leading to satisfaction, Achievement, Recognition, Responsibility and Growth and development.

\section{Expectancy Theory}

Vroom (1964), in an influential work, focused his attention on individual behavior in the work place. He observed the work behaviour of individuals with the object of explaining the processes involved. He assumed that most of the observed behavior would be motivated, i.e. That it was the result of preferences among possible outcomes and 52 expectations concerning the consequences of actions. His principal methodology was objective observations"e. The essential elements of Vroom's ideals have come to be called "Expectancy theory". The crux of this theory is that motivated behavior is a product of two key variables: The valence of an outcome for the individual, and the expectancy that a particular act will be followed by a predictable outcome. Valence is the anticipated satisfaction from an outcome. This distinguishes it from the value of the outcome, which is the actual satisfaction obtained. Expectancy is a momentary belief concerning the likelihood that a particular act will be followed by a particular outcome. The product of valence X Expectancy is force. Force is used in the sense of pressure to perform an act. Thus, the basic formula designed by Vroom can be stated as follows: Force $($ Motivation $)=$ Valence $\mathrm{X}$ Expectancy

Vroom's ideas have been pursued by numerous other theorists to the extent that in his review of motivation theory, Guest (1984) concluded that „Expectancy theory continues to provide the dominant framework for understanding motivation at work ${ }^{e e}$. Lawler \& Porter (1967), in particular, have extended

\section{The Trait-Factor Theory}

This theory of career knowledge was propounded by Holland (1997). The Trait-Factor Theory based career knowledge was perhaps the earliest approach to career development and emerged in direct response to the need for accurately matching people to specific occupations. This theory rests on a set of assumptions. Firstly, it is assumed that individuals possess a unique combination of traits, which can be measured and quantified with accuracy. It is further assumed that the characteristics of occupations are such that workers must exhibit certain specific traits for successful execution of the job roles of a particular occupation. Based on these two assumptions, the Trait-Factor approach attempts to identify and quantify the traits that characterize an individual and match the person with occupations that would draw from his or her unique profile of traits. This approach, therefore, describes career decision-making to be a simple process of matching personal characteristics with job requirements.

Accordingly, the closer the match, the greater the likelihood of optimal productivity and personal satisfaction. In other words, career success is contingent on finding the closest match between the individual's traits and the demands of a particular occupation.

Frank Parson (1909), in his seminal publication, 'Choosing a Vocation' outlined the Trait-Factor approach. He described career decision-making to be a rational process of identifying personal traits and then matching them with suitable careers. Frank Parsons' (1909) steps to rational career decision-making process:

- First of all, the individual using the expert services of a vocational guidance counselor needs to inform him or herself of personal aptitudes, interests and Satisfaction resources. This includes understanding personal limitations and the causes underlying these limitations.

- Next, the career chooser needs to acquire information about the conditions that promote occupational success.

- Finally, the individual arrives at a career choice through a rational and reasoned analysis of the relationship between the facts acquired at steps one and two. According to the Trait-Factor formulation, career decisionmaking is a rational process of problem solving, which is based on the systematic collection of information, the verification of this information and finally using this information to make a career decision. This was the approach that dominated career counseling in the West from the early 1900's to around the 1940's.

In the modern form, trait-and-factor theory stresses the interpersonal nature of careers and associated lifestyles as well as the performance requirements of a work position. Holland (1970) identifies six categories in which personality types and occupational environments can be classified: realistic, investigative, artistic, social, enterprising, and conventional (RIASEC). According to prestige levels, investigative (I) occupations rank highest, 
followed by enterprising (E), artistic (A), and social (S) occupations, which have roughly the same level of prestige. The lowest levels of prestige are realistic (R) and conventional (C) occupations (Gottfredson, 1981). The theory of career choice propounded by John Holland (1959) more than 40 years ago is perhaps the most well-known and widely studied career theory in the history of Career Psychology. This is probably because the theory has yielded objective methods for the practice of career counseling.

At the heart of Holland's theory there are three propositions: Firstly, it is possible, according to Holland, to classify people and environments into types. Type by definition, is a conglomeration of traits which can serve as a measure for categorizing people into groups. In Holland's formulation, there are six types of people and work environment. These are the realistic, investigative, artistic, social enterprising and conventional (RIASEC). The realistic type is the person who is most comfortable being involved in activities that are concrete and based on clearly defined systems and norms. Conversely, the realistic type of person is not comfortable in social contexts that require interpersonal skills, expressive ability and situations that require the expression of emotional sensitivity. Engineers, machine operators and mechanics are examples of professionals who would fit into Holland's realistic type.

The investigative type is analytical in orientation and enjoys drawing conclusions from systematic and objective observations. Repetitive and routine activities are likely to be avoided by this group of people. Researchers, doctors, detectives are examples of the investigative type. The artistic type thrives on being expressive and original. This type tends to be unconventional and deeply sensitive to personal feelings, thoughts and ideas. Activities that are orderly and mechanical are likely to be unattractive to this group. Actors, designers, musicians, authors would demonstrate the characteristics of the artistic type.

The social type is strongly oriented to human interactions. These people are sensitive to human needs, nuances of emotions, thinking patterns and other aspects of human behavior. Activities that occur in non-human situations are likely to be avoided. Counselors, nurses, teachers, social workers would fit into the social type. The enterprising type is typically self-driven. An individual from this group would enjoy organizing people, objects and resources to create systems and structures for the attainment of goals and targets. The enterprising type is likely to be uncomfortable in work situations that are repetitive and do not allow for leadership or the expression and implementation of personal ideas. Sales people, managers, politicians are said to possess the characteristics of the enterprising type. The conventional type tends to find the highest level of comfort in situations that are organized and predictable. They are likely to enjoy activities that require routine and repetition. Unpredictable, disordered situations and activities that require innovation are likely to be avoided. Accountants, bankers, receptionists would fall into the category of the conventional type. In an analysis of census data using the Holland codes, Reardon, Bullock and Meyer (2007) confirmed that the distribution across Holland's types is asymmetrical. They found that from 1960 to 2000 "the Realistic area had the largest number of individuals employed and that the Artistic area had the fewest number employed". The gap between the number of people employed in the Realistic and Enterprising areas shrunk during the five decades to where in 2000 there were approximately equal numbers of people employed in both areas. Interestingly, the Investigative area more than doubled during this time whereas

the other four areas remained relatively stable. Regardless of age, between $75 \%$ and $85 \%$ of male workers were employed in the Realistic and Enterprising areas; women were more varied and concentrated in Conventional, Realistic, Social and more recently Enterprising areas. Personal satisfaction in a work setting depends on a number of factors, but among the most important is the degree of congruence between personality types.

\section{Theory $X$ and Theory $Y$}

In his theory McGregor developed two distinct preconceived perceptions of how people observe human behaviour at work and organizational life. He believed that companies follow one of the two opposing approaches. He called these approaches theory X and theory Y. He argues that in theory X, management has the responsibility to ensure that the productive elements of the enterprise are organized such as money, materials, and people with the purpose of meeting economic ends. People have an inborn dislike of work and tend to avoid it whenever an opportunity arises. They are inborn selfish, indifferent to the needs of the organization, people's efforts need to be directed through motivation. controlling their actions and modification of their behaviour so as to fit organizational needs, they always need to be directed to take responsibility and have little or no ambition but above all everything they seek security.

Due to the lazy inherent nature of human beings they are not able to perform well in their own initiative. In order to make people to achieve the organizational objectives they need to be persuaded, rewarded, coerced, controlled, directed or threatened with punishment. The role of management into coerce and control employees. if 
management does not have an active intervention, people tend to remain passive and resistant to the needs of the organization. On the other hand, theory $\mathrm{Y}$ stipulates that management is charged with the responsibility to organize the elements of productive enterprise such as money, materials, equipment and people with the aim of meeting economic ends. To people work is a natural thing, they are not passive or resistant to organizational needs and are always ready to express self-direction when committed to the objectives because people are naturally not lazy. Unlike theory X people accept and seek responsibility at all times.

However, the only way management can ensure that people are committed is to provide them with the right conditions and operation methods to enable them achieve their goals through the direction of their efforts to meet objectives of the organization. In the assumptions suggested in theory Y, management's role is to develop employee's potential and help them to release that potential towards the achievement of common goals. Management in accomplishing its tasks uses these assumptions as guides and this leads to a variety of possibilities which fall between two extremes. In one extreme side management can be hard or strong and on the other management can be soft or weak. Theory $\mathrm{X}$ is the standpoint that traditional management has taken towards the work force while many modern organizations are now taking the enlightened position of theory $\mathrm{Y}$ (Boeree, 2006). Me Gregor's theory Y is linked to the questions in the questionnaire that are concerned about training, monitoring performance, performance assessment working conditions.

\section{REVIEW OF EMPIRICAL STUDIES}

\section{Job Incentives on Workers Performance}

Adequate incentives have been found to be one of the means which organization can adopt to motivate and increase their workers' performance. There are many studies which examine the monetary and nonmonetary incentives and their effects on organizational variables (Nsour \& Scheepers 2009). Incentive programs are put in place by various organizations to compensate and reward performance of employees who perform more than expectation (Schiller 1996). Incentive packages are financial or non-financial rewards offered to employees to compel them to exert more effort into any giving task (National Commission on Productivity and Work Quality 1975). Incentives is a force that cause employees to behave in certain ways and on any given day, they may choose to work as hard as possible at a job, to work just hard enough to avoid a reprimand, or to do as little as possible (Griffin, 2002). Meanwhile, incentives are designed to get the maximum performance from the employees and help retain the most productive among them (Arnold 2013).

Organization can consider a variety of ways to reward the employees for their work performance, but an organization need to consider using the best employee incentives to get the desired results. Incentives are an instrumental drive towards employee motivation and performance and it has great benefits and high potentials to motivate workers to put in their best in any giving task (Condly, 2003). "High productivity may be determined by workers employees that are not well rewarded produce less" Koontz (1984).

Luthans (1998) divided these incentives into monetary incentives and non-monetary incentives which is also known as financial or non-financial incentives. Meanwhile, employees could be intrinsically or extrinsically motivated. Intrinsic motivation is an inward drive coming from within the person which makes him to work effectively and efficiently toward the realization of organizational productivity (Ryan \& Deci 2000). It arises from natural psychological needs, such as needs for competence and autonomy (Deci \& Ryan, 1985; Kasser \& Ryan, 1996). It is a self-generated urge that comes from inside an employee and influences him/her to work harder. They are connected to job related and social incentives such as opportunity to use one's ability, interesting work, recognition of a good performance, development opportunities, a sense of challenge and achievement, participation in decision making, and being treated in a caring and thoughtful manner etc. On the other hand, extrinsic motivation exists when behaviour is performed to attain externally administered incentives. Extrinsic motivation is related to "tangible" incentives such as wages and salaries, fringe benefits, cash bonuses, security, promotion, wall plaques, free dinner or movie tickets etc. (Pattanayak, 2005) Intrinsic and extrinsic incentives are two important tools in ensuring motivation, commitment and satisfaction of employees in the world of work. It is therefore possible to state that nonmonetary incentives as a motivational tool address both intrinsic and extrinsic motivation concepts. While monetary incentives may only be classified as a factor leading to extrinsic motivation. Therefore, for employees to remain efficient and highly productive, and competitive, management need to understand why individuals and group behave the way they -do, so that they can be satisfied, happy and highly productive (Oyedijo, 1995).

The term incentive refers to something that intends to ignite one and or calls for greater effort to act in a given manner. In the study an incentive referred to an inducement that is given to the health professionals in an organization in order to motivate, encourage and maintain a desired behaviour (Allen and Kilmann, 2001). 
According to Hicks and Adams (2003), incentives are mechanisms aimed at achieving a specific change in behaviour. Whereas performance refers to how well an employee fulfils assigned task through effort and skill, an incentive refers to an inducement for a desired action. Incentive pay is a form of compensation given to workers upon attainment of some form of job performance (Armstrong, 2009). Organizations have resorted into the adoption of relevant and appropriate incentives in order to encourage workers to elicit their best skills while increasing their effort (Yap et al., 2009).

Various forms of incentive plans are offered to workers, such as commission and bonus awards. Similarly, Franco (2002) identified incentives as a means applied by the employer so as to influence the health professionals' willingness to exert and maintain effort towards attaining organization goals. Incentives are used by organizations in order to reach certain goals, encourage a certain behavior and team-spirit for collective awards. Incentive systems are not universally applicable, but are likely to play a role in enhancing individual effort or performance where the conditions and the scheme designed are right (Manjunath and Rajesh, 2012). A balanced incentive program introduced in an organization is likely to motivate employees and as a result lead to improved performance (Petrescu and Simon, 2008).

Both monetary and non-monetary incentives can be used in this case. However, it has been shown that nonmonetary incentives are proving themselves as being more effective tools in the workplace than the monetary incentives (Nolan, 2012 and Priyce et al., 2011). There is need to link the individual workers incentives to the organizational objectives in order to provide them with a touch or a feeling of ownership of their assigned jobs (Lee and Chen, 2011). Unlike individual incentives, the group incentives encourage team spirit. For example, when each worker in the group realizes that they all have equal responsibility in attaining a certain performance target, they encourage one another to work harder, by virtue of the fact that one's gain depends on the partner's input to performance (Chiu, 2002).

\section{Career Knowledge and Workers Performance}

The management of worker incentive and career knowledge are today more complex than it had hitherto been some four decades ago. This is because many unanticipated legal, social, cultural and economic constraints have surfaced in recent time (Banjoko 2006). The dynamic nature of the environment has altered the values and expectation of the workers thus putting pressure on workers to review upwards the contents of any compensation package. The economic situation of Nigeria has changed drastically in recent time such that cost of living has shut up drastically, cost of operation has increased and competition has become more intense. Workers with high level of knowledge are more sensitive to the value they create and the reward they get in form of wages and benefits.

Workers through their unions now argue that if they had put in so much effort to help the organization to create value, it is only fair that they be given a fair bite of the cake. Consequently, there are often more frequent demands for pay increases from workers in all the sectors of the economy. Incentive management is no doubt one of the most problematic and significant aspects of human resources management. Consequently, the cardinal objectives of incentive management are to put forward incentive structures as well as implement these incentive processes in a manner that would enhance both individual and organizational effectiveness. In this regard, some of the following consideration may become quite imperative; rewarding positive work behaviour while sanctioning undesirable work behaviour, ensuring equity and fairness.

Incentive and career knowledge are the centerpieces and manifestations of an exchange relationship between the workers and employers. In situation of high competition in the business environment, the attainment of high organizational productivity must recognize the need to inspire and motivate the workers who perform excellently in their career knowledge via the design, establishment and implementation of a robust incentive system that calls out the best in the workers in terms of their performance, commitment, dedication and loyalty. The process of effectively managing any organizations incentive systems is undoubtedly one of the most complex and problematic issues in human resources management.

There has been more information produced in the last 60 years than during the previous 2000 years. Information is very important to everyone. We define the people who access and use significant portions of this exploding information resource as knowledge workers. Success for the organizations will be based not just on what the growing number of knowledge workers know, but on how fast they can learn and share their knowledge, the latter is related. Knowledge workers are unlike previous generations of worker, not only because of their access to educational opportunities, but because they own the means of production, i.e., knowledge that is located in brains, dialogue and symbols. The most important contribution management needs to make in 21 st century is to increase the productivity of knowledge work and knowledge workers. As a consequence, productivity is 
dependent on the contributions of specialist knowledge workers. Among the more widely-accepted conceptualizations of career is that of Hall (2003) who defines a career as a sequence of related work experiences and activities, directed at personal and organizational goals, through which a person passes during his or her lifetime, that are partly under their control and partly under that of others.

We view knowledge workers' career as ongoing sequence of education and job activities that are meaningful to the individuals and that add value to the organizations in which the individuals participate. This is due to the general recognition that these concepts have important implications for individual behaviors and work outcomes and both affect the implementation process of the psychological employment contract. Career success is a way for individuals to fulfill their need for achievement and power. Because it improves people's quantity or quality of life, the study of who can get ahead and why is of interest and value Career success has received significant attention in studies of the organizational behaviours. Research on career success benefits not only individuals but also organizations. At the individual level, career success refers to acquisition of materialistic advancement, power, happiness and satisfaction.

Career Knowledge helps individuals develop appropriate strategies for career development. At the organization level, knowledge of the predictors of career success helps human resource managers design effective career systems. A number of competing approaches have been identified to explain career success predictors. The three well-known approaches are the individual, the structural, and the behavioural perspectives (Banjoko, 2006).

Job incentive management is concerned with the design of appropriate incentive structures, policies and procedures in addition to implementing and maintaining the processes in a manner that would promote and enhance individual and corporate effectiveness. Incentive management is most successful, when it incorporates the goals and the aspirations of the major participants in the labour management exchange process (Banjoko 2006), these are the organizations, the individual worker and the labour union. The organization's goals and objectives include growth, profitability and enhanced survival. The individual's goals and objectives include personal growth and development, security of employment opportunities, improved career prospects and welfare. On the part of the unions, their goals include security of jobs for their members, improved welfare packages and a stronger voice in the conduct of the affairs of the organization (Banjoko 2006)

A good and well-structured incentives system and career knowledge should be able to accomplish some objectives or some desirable outcomes which in the final analysis would be able to enhance the attainment of corporate goals and objectives.

The design and structure of an organisation's incentives system is expected to have positive impacts on individual behaviour and corporate performance. It would be a serious disaster if after designing and implementing a high-profile incentives system, problems start to surface and companies now find themselves with compensation systems that have negative impacts.

\section{METHODOLOGY}

The study employed a descriptive research design. A total of one hundred respondents participated in this study. Purposive sampling techniques were used to collect data from the respondents. The sample included both male and female. The instrument used for the study was a structured questionnaire that consisted of fifty (55) questions divided into four sections. Section A contained socio-demographic information; Section B contained information on Job Incentives. Section C contained information on Career knowledge and Section D contained information on Employee Performance.

The data generated were checked, clean and analyzed using the Statistical Package for Social Science (SPSS). Data collected in the study was subjected to inferential and descriptive statistics. Specifically, the data were analyzed using the simple percentage, and frequency counts for the socio- demographic information, while Pearson product moment correlation was used for testing of the hypotheses of the study.

\section{PRESENTATION OF DATA}

\section{Analysis of Demographic Information}

The table above reveals the case summary of frequency of the respondent's gender with the valid percentages of their responses, it shows that 54 questionnaires were responded to and retrieved from male with $54 \%$ valid and 46 questionnaires were retrieved from female with $46 \%$ valid. As it is being revealed, the distribution of questionnaire was random, no gender discrimination. In the table above, the various frequencies of the respondents' age were revealed. This study has 26 respondents whose age was below 30 years which was represented by $26 \%, 48(48 \%)$ out of the respondents have their age between 31 and 40 years, $16(16 \%)$ of the respondents are between 41 and 50 years of age, while $10(10 \%)$ respondents' age was above 50years. The above 
table shows the marital status of the respondent with their frequencies i.e. Married has 72 frequencies with $72 \%$, Single has 20 frequencies with $20 \%$ valid and this study has $8(8 \%)$ divorcees, and a respondent decline information on this. In this table, $2 \%$ of the respondents have WASC/GCE, $21 \%$ have OND/NCE, $57 \%$ of them had have Bachelor's degree/HND and 19\% has Higher Degrees. A respondent did not supply information about his educational qualification. This attested to the fact that the questionnaires were distributed regardless of the qualifications of the respondent. The above table shows that $24(24 \%)$ of the respondent's top management staff, $58(58 \%)$ of the respondent are middle management staff, while $17(17 \%)$ of the respondents are low management staff of the organisation. One respondent however did not indicate his level representing $1 \%$.

\section{Test of Hypotheses}

The results of the study on the basis of the hypotheses generated for the study.

Hypothesis 1: Job Incentives will not significantly influence job performance of employees Transmission Company of Nigeria (TCN)

The result in table 2 above revealed that Job Incentive was weakly and negatively related to job performance [r $(96)=-0.11, p>0.05]$. Therefore, the hypothesis was supported by the result of the study, and it is subsequently accepted. Thus, it is concluded that Job Incentives has weak negative relationship with job performance.

Hypothesis 2: Career Knowledge will not significantly influence job performance of employees Transmission Company of Nigeria (TCN)

The result in table 4.7above revealed that Career Knowledge was weakly and positively related to job performance $[\mathrm{r}(96)=0.119, \mathrm{p}>0.05]$. Therefore, the hypothesis was supported by the result of the study, and it is subsequently accepted. Thus, it is concluded that Career Knowledge has weak positive relationship with job performance.

\section{DISCUSSION OF FINDINGS}

The first hypothesis was tested with a Pearson Correlation and the findings show that that Job Incentives has weak negative relationship with job performance. The findings revealed that the level of job incentives in a work place has a weak negative relationship with job performance. Job incentives is the process of creating organizational conditions which will impel employees to strive to attain company goals

Looking at the empirical literature, the findings of this study support the findings of many researchers who have examined the relationship between job incentives and employee's performance. According to Hodgetts (1977), job incentives is the influence or drive that causes employees to behave in a specific manner and has been described as consisting of energy, direction and sustainability. According to Griffin (2002), job incentives is a force that cause employees to behave in certain ways and on any given day, they may choose to work as hard as possible at a job, to work just hard enough to avoid a reprimand, or to do as little as possible. According to Arnold (2013), job incentives are designed to get the maximum performance from the employees and help retain the most productive among them

The second hypothesis was also tested and revealed that career knowledge has weak positive relationship with job performance among workers of Transmission Company of Nigeria. According to Banjoko (2006), career knowledge helps individuals develop appropriate strategies for career development. At the organization level, knowledge of the predictors of career success helps human resource managers design effective career systems. A number of competing approaches have been identified to explain career success predictors. The three wellknown approaches are the individual, the structural, and the behavioural perspectives.

According to Hall (2003), the most important contribution management needs to make is to increase the productivity of knowledge work and knowledge workers. As a consequence, productivity is dependent on the contributions of specialist knowledge workers.

\section{CONCLUSION}

Based on the findings of this study, we can conveniently conclude that job incentive is an important factor that employers and labour need to take care of. This is so because it affects workers job performance. Also Job Career Knowledge is another major factor that organization management needs to review from time to time. Training and seminars on career knowledge needed to be organized periodically to update the workers career knowledge.

\section{RECOMMENDATIONS}

From the findings of this study, the following hereby recommendations are made Employers should do more on 
adequate job incentives and rewards to their employees to elicit positive attitude from them at work; and achieve job satisfaction which improves employee productivity and corporate performance. Giving job incentives should be linked practically with the level of performance so as to distinguish the excellent employees according to their performance; this will enhance the employees to do their best in order to improve their performance, and therefore job incentives will be linked to improving the performance of employees in the organization.

\section{References}

Abbas A. (2009):"Motivations and their Effects on Performance": Creating an intrinsically motivating environment. Academy of Management Journal 93(31) 120-129

Alfares S. (2011):"The Effect of Incentives Strategies on Organizational Loyalty in Public Sector": Effective incentives and Organizational Culture. Journal of management Studies 32(11)

Alnsour M. (2012):"Relationship between Incentives and Organizational Performance for Employees in the Jordanian Universities: Making human productivity a science. Performance and Instruction. Journal of Organizational Performance 24(1)3-9.

Azoulay C. (2011): Incentives and creativity: Evidence from the academic life sciences. In G.B Rossman, C. Mashall \& T.Lopez (Eds.).Handbook of Motivational Incentives and Creativity (pp.123142):San Francisco: Jossey Bass.

Banjoko S.A. (1996): Human Resource Management: Pumark Nigeria Limited, Pp. 72-85.

Ederer G.A (2011): Is pay-for-performance detrimental to innovation? Academy Management Journal 30(7) $48-56$

Gana A.B. (2011): "The Effects of Motivation on Workers Performance. How to improve employee performance? Journal of management Studies 22(6).

Herzberg F. (1957). Job attitude: Review of Research and Opinion. Pittsburgh.

Jenkins D.G. (1998): Are financial incentive related to performance? A meta-analytic review of empirical research-Beverly Hills, Calif: Sage Publication.

Kreitner R. (2001): Organizational Behaviour (5th ed.). Burr Ridge, ILL: Irwin/McGraw-Hill.

Locke H.S. (1980): The relative effectiveness of four methods of motivating employee performance. In Duncan, K.D; Gruenbery, M.M and Wallis, D. (Eds.)1980. Changes in working life. (Pp.363388) New York: Wiley.

Shanks N.H. (2012): Management and motivation. High Motivation equals high Happiness. Englewood Cliffs, NJ: Prentice-Hall

Society for Human Resource Management (2009): Employee job satisfaction: Understanding the factors that makes work gratifying. 6-17. Web. 14 Feb.2012.

William R. (2012): A study of motivation: How to get your employees moving. Indiana University. 
Table 1: Socio-demographic Characteristics of the Respondent

\begin{tabular}{|c|c|c|c|}
\hline Variable & $\begin{array}{l}\text { Socio-Economic } \\
\text { Variables }\end{array}$ & Respondents & Percentage \\
\hline \multirow[t]{3}{*}{ Gender } & Male & 54 & 54.0 \\
\hline & Female & 46 & 46.0 \\
\hline & Total & 100 & 100 \\
\hline \multirow[t]{5}{*}{ Age Group } & 20-30 years & 26 & 26.0 \\
\hline & $31-40$ years & 48 & 48.0 \\
\hline & $41-50$ years & 16 & 16.0 \\
\hline & 50 years and above & 10 & 10.0 \\
\hline & Total & 100 & 100 \\
\hline \multirow[t]{4}{*}{ Marital status } & Single & 72 & 72.0 \\
\hline & Married & 20 & 20.0 \\
\hline & Divorced & 8 & 8.0 \\
\hline & Total & 100 & 100 \\
\hline \multirow[t]{5}{*}{ Education Qualification } & SSCE/GCE & 2 & 2.0 \\
\hline & $\mathrm{OND} / \mathrm{NCE}$ & 21 & 21.0 \\
\hline & $\mathrm{HND} / \mathrm{BSC}$ & 57 & 57.0 \\
\hline & MBA/MSC/P.hD & 20 & 20.0 \\
\hline & TOTAL & 100 & 100 \\
\hline \multirow[t]{4}{*}{ Length of Service } & Top Management & 24 & 24.0 \\
\hline & Middle Management & 58 & 58.0 \\
\hline & Low Management & 18 & 18.0 \\
\hline & Total & 100.0 & 100 \\
\hline
\end{tabular}

Source: Author's Fieldwork, (2018)

Table 2 A summary table of Pearson, $r$ correlation showing the relationship between Job Incentives and job performance of employees Transmission Company of Nigeria

\begin{tabular}{r|cccccc}
\multicolumn{1}{c}{} & N & Mean & S. D & df & r & p \\
Job Incentive & 98 & 18.9694 & 3.11118 & 98 & -.111 & .145 \\
Job Performance & 98 & 51.5000 & 8.44049 & & &
\end{tabular}

Table 3 A summary table of Pearson, $r$ correlation showing the relationship between Career Knowledge and Job Performance of employees Transmission Company of Nigeria
$\mathrm{N}$
$\mathrm{M}$
Std. D
Df
$\mathrm{r}$
$\mathrm{p}$

\begin{tabular}{r|rrrrrr} 
Career Knowledge & 98 & 9.7216 & 1.68784 & 98 & .119 & .131 \\
Job Performance & 98 & 51.5000 & 8.44049 & & &
\end{tabular}

